\title{
PARA ALÉM DAS ESPÉCIES: A BUSCA POR UM CONCEITO JURIDICAMENTE ADEQUADO PARA OS ANIMAIS NO DIREITO BRASILEIRO
}

\section{BEYOND SPECIES: THE QUEST FOR AN ADEQUATE LEGAL CONCEPT FOR ANIMALS IN BRAZILIAN LEGAL SYSTEM}

\author{
${ }^{1}$ Carolina Maria Nasser Cury \\ ${ }^{2}$ Lais Godoi Lopes
}

\section{RESUMO}

O presente trabalho analisa a questão do tratamento juridicamente adequado de animais. Para tanto, efetuou-se a desconstrução da importância do critério de espécies para a justificativa da separação entre humanos e animais. Posteriormente, buscou-se analisar, também, as principais teorias éticas que superam o especismo e que endereçam as questões pertinentes aos direitos dos animais. As três teorias abordadas foram o abolicionismo animal, o recorte kantiano aos direitos dos animais e o enfoque utilitarista. Abordou-se as diferenças dos vieses abolicionista, kantiano e utilitarista, no que tange à consideração jurídica de animais. Finalmente, apresentou-se um critério alternativo às proposições atuais em sede de direitos dos animais, que visa à superação da dicotomia entre coisas e pessoas no Direito.

Palavras-chave: Direitos dos animais, Especismo, Abolicionismo, Viés kantiano, Utilitarismo

\begin{abstract}
This paper examines the issue of the proper legal treatment of animals. To this end, we debunked the importance of the criterion of species for justifying the distinction between humans and animals. Then, we also sought to analyse the main ethical theories that overcome speciesism and its legal repercussions. We then discussed three theories, which are animal abolitionism, Kantian approach to animal rights and the utilitarian view. We addressed the differences between abolitionists, Kantian, and utilitarian bias regarding legal consideration of animals. Finally, we presented an alternative criterion to the current proposals regarding animal rights, which aims to overcome the dichotomy between things and persons on Law.
\end{abstract}

Keywords: Animal rights, Speciesism, Abolitionism, Kantian account, Utilitarianism

\footnotetext{
${ }^{1}$ Mestre em Direito pela Universidade Federal de Minas Gerais - UFMG, Belo Horizonte - MG (Brasil). E-mail: carolnasserc@gmail.com

${ }^{2}$ Doutoranda em Direito na Universidade Federal de Minas Gerais - UFMG, Belo Horizonte - MG (Brasil). E-mail: laisglopes@gmail.com
} 


\section{INTRODUÇÃO}

A história evolutiva da humanidade interpenetra-se à inserção, utilização e domesticação de animais não-humanos ${ }^{1}$. Sociedades humanas desenvolveram-se, em grande medida, em função da troca de experiências de mimetização, exploração e contato com outras espécies, que culminou em um grau elevado de variações de habilidade que direcionaram a dinâmica do desenvolvimento evolutivo.

Tanto o envolvimento direto entre seres humanos quanto o envolvimento com componentes não-humanos do ambiente foram imprescindíveis para o caminho evolutivo do Homo sapiens. Nesse sentido, as mudanças que fixaram sociedades como caçadorascoletoras, pastorais ou domesticadoras são responsáveis por fornecer alterações qualitativas tanto em animais quanto em seres humanos (INGOLD, 2000, p. 61).

A própria evolução genética humana é pautada pelo estilo de relação desenvolvida entre humanos e animais. A revolução agrícola, período pré-histórico caracterizado pelo início do sedentarismo dos humanos que coincide com a passagem do paleolítico para o neolítico, culminou na proximidade, nunca antes experimentada, de seres humanos, porcos e galinhas (BOCQUET-APPEL, 2011, p. 560-561). Essa proximidade entre espécies foi diretamente responsável pelo filtro no pool genético humano, que, com a inserção de patogênicos exógenos, a seleção natural foi direcionada à imunidade a tais patogênicos. Finalmente, a domesticação de animais leiteiros foi responsável por outra alteração no pool, já que foram selecionados genes com menor propensão à alergia forte à lactose (BUCHANAN, 2011, p. 17).

Contemporaneamente, a relação entre espécies tem obtido um crescimento inédito, em termos quantitativos. Estima-se que haja, somente no Brasil, 37 milhões de cães e 21 milhões de gatos domesticados. O recenseamento demográfico em questão abrange somente a população animal que vive em casas ou abrigos, desconsiderando a população de rua ${ }^{2}$. Ao todo, estima-se que há, em território brasileiro, cerca de 100 milhões de animais domésticos - uma média de dois animais por família brasileira. Em torno dessa relação, um expressivo faturamento de $\mathrm{R} \$ 16$ bilhões foi calculado pela Associação Brasileira da Indústria de Produtos para Animais de Estimação para o ano de 2014 (CRESCE, 2015).

Ainda, estima-se que mais de 100 milhões de animais foram utilizados, somente nos Estados Unidos, para fins de pesquisa científica e cosmética. No Brasil, os dados numéricos são imprecisos e vagos. Contudo, departamentos governamentais dos Estados Unidos, Canadá

\footnotetext{
1 Doravante, animais.

2 Que, por ausência de políticas públicas eficientes, tende a aumentar.
} 
e Reino Unido contabilizam que cerca de 11.558.837 animais foram usados em testes diversos, durante o ano de $2013^{3}$.

Finalmente, a indústria alimentícia é responsável por uma média de 8,3 milhões de cabeças de bovinos abatidas por trimestre, conforme dados de 2014. De acordo com o Instituto Brasileiro de Geografia e Estatística - IGBE, esse número trimestral abrange somente aqueles abatedouros regularizados e constantemente fiscalizados no Brasil - ao menos 30\% da carne produzida no Brasil é feita sem qualquer fiscalização (FANTÁSTICO, 2013), e esses números são ainda maiores em função da fiscalização em estados grandes produtores, como os da Região Centro-Oeste e os da Região Norte (IBGE, 2015).

Percebe-se, através da análise desses nichos de relação entre humanos e animais, que esses ora são tratados como um importante elo dentro de uma família, ora como commodities, ou, bens. $\mathrm{O}$ aumento do uso de animais e a divulgação midiática dada às polêmicas geradas pela relação humano-animal impulsionaram debates acerca da eticidade e juridicidade do uso de animais por seres humanos ${ }^{4}$.

A resposta jurídica ao problema dessa relação é extremamente lacunosa e imprecisa. Parte-se do pressuposto de que animais não-humanos são bens semoventes, conforme estipula o art. 82 do Código Civil brasileiro, sem que demais considerações sobre o status jurídico de animais sejam elaboradas.

O presente trabalho visa a analisar as justificativas ético-jurídicas que buscam fundamentos para a proposição de direitos aos animais, bem como propor uma adequação do status de animais no Direito brasileiro.

\section{ENTRE HUMANOS E ANIMAIS: A INSUFICIÊNCIA DO CRITÉRIO DE ESPÉCIES PARA A ABORDAGEM JURÍDICA DO PROBLEMA}

As relações entre humanos e animais impactam o mundo em uma escala global. Elas influenciam desde a preservação de um meio-ambiente sustentável até a viabilidade de condução de experimentos científicos para o progresso de áreas como a saúde. A despeito da

\footnotetext{
3 Conforme dados obtidos em relatórios oficiais dos seguintes países: ESTADOS UNIDOS, Departamento de Agricultura, Serviço de Inspeção de Saúde de Animais e Plantas. Annual Report Animal Usage by Fiscal Year,

28 Nov. 2014. CANADÁ, Conselho Canadense sobre Cuidados Animais. CCAC 2011 Survey of Animal Use, Dez. $2010 . \quad$ REINO UNIDO, Estatísticas Anuais dos Procedimentos Científicos em Animais Vivos na Grã Bretanha, 10 Jul. 2014.

4 Conforme denota a comoção pública gerada pelo resgate de cães da raça Beagle das instalações do Instituto Royal, em outubro de 2013.
} 
importância das relações entre espécies, o Direito brasileiro analisa os usos de animais por humanos em uma ótica simplista: a que denota a coincidência de animais como bens.

Nesse sentido, animais de diferentes espécies, inseridos em contextos sociais diferentes, são analisados sob um único viés estruturante: o estatuto de bens, pautado pela importância valorativa conferida à noção de espécie. Como justificativa a esse tratamento, alega-se que a espécie humana destaca-se das demais por possuir características superiores, o que acaba por polarizar humanos e animais.

As definições de fronteiras em lógicas dicotômicas são muito mais difíceis do que se pode imaginar. Em grande parte, essa dificuldade é devida à complexidade de relações desenvolvidas entre duas categorias que pretendem ser fixas, mas desempenham uma ausência de padronização estanque, sendo categorias abertas em função de tempo, espaço, cultura, biologia e ambiente. Essa é justamente a dificuldade do caso da busca por uma categorização do status de animais com base no critério de espécies.

\subsection{A dicotomia entre humanos e animais com base no pertencimento a uma espécie}

A narrativa humana de sua história busca enfatizar a existência de um hiato qualitativo substancial entre a espécie Homo sapiens e os demais animais. Elencam-se critérios como a posse de um self - ou mesmo de uma alma, de uma racionalidade ou domínio do ambiente e da linguagem, como elementos distintivos capazes de traçar uma ruptura entre o que deve ser o universo de ação humana e o dos animais. Atualmente, o critério utilizado para que humanos sejam analisados em separado dos animais está no pertencimento à espécie Homo sapiens 5 .

A ruptura delineada entre os seres humanos e os animais gera uma escala hierárquica de valores fundamentada na espécie. Nesse sentido, entende-se que os seres vivos que pertencem à espécie humana possuem características superiores que não são compartilhadas, em todo ou em partes, com demais espécies. Com isso, a estatura valorativa dos seres

\footnotetext{
${ }^{5}$ Os critérios citados podem ser encontrados em diversos autores, ao longo do desenvolvimento da história e da filosofia ocidentais. Entretanto, o argumento que distingue humanos de animais pela posse de uma alma é tônica do pensamento escolástico. Seres humanos, somente, seriam criados à imagem e semelhança de um Deus, e seriam integrados tanto por componentes materiais quanto imateriais (uma alma). Cf. STONE, M. W. F. The soul's relation to the body: Thomas Aquinas, Siger of Brabant and the Parisian debate on monophysicism. In: CRANE, Tim. PATTERSON, Sarah. History of the mind-body problem, London: Routledge/Taylor and Francis e-library, 2002, p. 34-35. Ainda, a ideia de racionalidade como elemento fronteiriço encontra-se melhor representada em René Descartes e na inseparabilidade dos pensamentos racionais do cogito. DESCARTES, René. Meditations on first philosophy. With selections from the objections and replies. Oxford: Oxford University Press, 2008.
} 
humanos é, portanto, superior à dos demais. O fato de um indivíduo ser humano constituiria razão suficiente para que ele seja tratado "com uma consideração maior do que a [que se tem] por membros das outras espécies” (RACHELS in GALVÃO, 2010, p. 187).

Esse motivo é frequentemente justificado tanto pelo pertencimento simples à espécie humana ou pela ideia de que o fato de um ser pertencer à espécie humana está correlacionado à posse de "outras diferenças que são relevantes" (RACHELS in GALVÃO, 2010, p. 190).

Assim, se um ser pertence à espécie humana, ele é, automaticamente, capaz de direitos e deveres na ordem civil, já que somente esses seres possuem a capacidade genérica para a contração de direitos e obrigações, por serem pessoas humanas.

O Direito brasileiro adota, assim, o critério de espécie como válido e relevante para a legalidade do tratamento de animais. Pode-se perceber essa adoção a partir da separação entre humanos como pessoas e animais como bens, ambas derivadas do estatuto das pessoas naturais e daquele concernente aos animais. De acordo com o art. $2^{\circ}$ do Código Civil brasileiro, "a personalidade civil da pessoa começa do nascimento com vida", sendo esse artigo destinado somente aos seres humanos. Ainda, o art. 82 estipula que são móveis "os bens suscetíveis de movimento próprio (...) sem alteração da substância ou destinação econômico-social", incluindo-se os animais nessa categoria.

A dicotomia entre humanos e animais é notadamente um exemplo da assunção de que a espécie, por si só, indica determinada estatura valorativa que é relevante juridicamente. Nesse sentido, ainda que animais possam experimentar estímulos vinculados a sentimentos de dor ou prazer, o seres humanos possuem interesses superiores aos desses animais, por possuírem caraterísticas únicas e especiais, vinculadas ao pertencimento à espécie Homo sapiens. Com isso, quaisquer interesses animais devem ser preteridos, se e quando em confronto com interesses humanos.

Muito embora a separação categórica entre humanos e animais com base no conceito de espécie possa parecer juridicamente válida, ela encontra-se flagrantemente equivocada.

Insta ressaltar que, ao dividir seres de modo valorativo através do conceito de espécie, infere-se que pertencer a uma determinada categoria taxonômica é um critério suficiente para que características superiores, importantes juridicamente, sejam observadas.

A busca por características isoladas que destaquem humanos dos animais é, entretanto, inócua. Os chamados marcadores da humanidade, isto é, características pontuais responsáveis pela distinção entre humanos dos demais seres tais como consciência de si, senso de 
historicidade, raciocínio lógico e linguagem, não podem ser elencados como critérios válidos para a separação valorativa do Homo sapiens dos demais (SINGER, 2002, p. 96).

Isso porque, independente da escolha do atributo, qualquer seja ele, ou (i) ele não estará presente em alguns seres humanos, ou (ii) ele estará presente em outros animais, fazendo com que formação de uma estatura juridicamente válida de uma determinada categoria, se fundada em um desses atributos, não possua validade.

Isso ocorre pois atributos como os acima citados não são tipos naturais, ou inatos. Antes, desenvolvem-se em um contínuo estritamente vinculado a ambientes informacionais, encapsulamento de informações e da própria conformação biológica de um ser vivo, pautados por um engajamento de mão dupla com o ambiente circundante (FLORIDI, 2011, p. 549556). Caso exista algum déficit substancial em tais processos, comportamentos considerados como "superiores" dificilmente emergirão: seja em animais humanos ou não humanos.

A premissa de que o pertencimento à espécie Homo sapiens é capaz de conferir, por si só, status valorativo relevante é bastante arraigada em contextos sociais do Ocidente. Conforme sustenta Peter Singer, “a concepção de que a vida humana tem um valor único está profundamente enraizada em nossa sociedade e é cultuada pelo nosso direito" (2002, p. 94).

Repetidamente, alega-se que a dignidade humana é "uma propriedade essencial que deve ser respeitada ou protegida, enquanto os 'direitos humanos' são, de modo similar, assumidos como patrimônio natural de seres humanos simplesmente por esses serem humanos" (CHAN, HARRIS in FREY, BEAUCHAMP, 2013, p. 304). Ainda, o antropólogo Tim Ingold afirma que

um ser humano é um indivíduo pertencente a uma espécie; existir como ser humano
é existir como pessoa. No primeiro sentido, o conceito de humanidade refere-se
a uma categoria biológica (Homo sapiens); no segundo, aponta para uma
condição moral (de pessoa). O fato de que empregamos a mesma palavra
'humano' para ambos os sentidos reflete a convicção profundamente arraigada
de que todos os indivíduos pertencentes à espécie humana - e exclusivamente
estes podem ser pessoas, ou, dito de outra forma, que a condição de
pessoa depende do pertencimento à categoria taxonômica (INGOLD, 1995, p. 8).

Nesse sentido, encontra-se, na Declaração Universal dos Direitos Humanos, em seu art. $1^{\circ}$, a afirmação de que "todos os seres humanos nascem livres e iguais em dignidade e direitos" (ONU, 1948). Ainda, o Pacto de São José da Costa Rica é enfático ao indicar, em seu art. 1", que "pessoa é todo ser humano" (OEA, 1978).

Entretanto, o desenvolvimento científico observado nos séculos XX e XXI culminou no surgimento de diversos estudos que dilapidam a noção de que o pertencimento à espécie 
humana é suficiente para que comportamentos superiores, como os pessoais, sejam desenvolvidos.

A discussão sobre o caráter exato da pessoalidade, ou seja, a qualidade de ser pessoa, ainda é um assunto em aberto, que não será objeto de estudo aprofundado no presente artigo. Entretanto, é possível afirmar que, de acordo com uma linha de raciocínio que remete a John Locke, em Ensaio sobre o entendimento humano:

\begin{abstract}
deve-se considerar o que significa Pessoa; que, penso eu, é um ser pensante e inteligente, que possui razão e reflexão, e pode considerar-se como a mesma coisa pensante em diferentes tempos e lugares; o que é feito apenas por essa consciência, a qual é inseparável do pensamento, e me parece ser essencial para ele (...) (LOCKE, 1964, p. 188).
\end{abstract}

A pessoa pode ser considerada, mas não resumida, como um ser que é capaz de conferir valor à sua existência e que, com isso, pode ser uma vida valorosa, ou, ainda, que vale a pena ser vivida (STANCIOLI, 2010, p.124-125) ${ }^{6}$.

Essa possibilidade encontra óbices a uma adequação somente à posse da característica de ser humano, conforme casos fronteiriços de seres humanos anencefálicos, em coma ou estado vegetativo permanente parecem indicar.

Até a concretização da teoria darwiniana da evolução, acreditava-se, via de regra, que a separação em qualidade de humanos dos demais seres era um produto de rupturas entre humanos e não-humanos. As divisões de características seriam abruptas e bem definidas: ou se possuía uma determinada característica, ou não. Contudo, a biologia desenvolvida a partir de 1950, "parece ter alterado o equilíbrio da questão filosófica sobre se as espécies são tipos naturais, com traços essenciais e universais, ou meramente conjuntos ou categorias nos quais, por conveniência, agrupamos as criaturas" (FERNANDEZ-ARMESTO, 2007, p.12). Essa ruptura permitiu com que se afirmasse que a espécie, por si só, possui pouca importância para avaliações ético-jurídicas, por possuir limites arbitrários e variáveis.

Assim, elaborar uma justificativa para o caráter da relação entre humanos e animais no viés especista ${ }^{7}$ é incorrer, também, em erro. O pertencimento a uma espécie é uma designação de classe, não uma revelação de uma essência (FERNANDEZ-ARMESTO, 2007, p. 12) - se é que essas existem.

\footnotetext{
6 O conceito que vincula a pessoalidade à escolha de uma vida que valha a pena ser vivida também está presente em: CHAN, Sarah. HARRIS, John. Human animals and nonhuman persons. In: FREY, Raymond. BEAUCHAMP, Tom (eds). The Oxford Handbook of Animal Ethics. Oxford: Oxford University Press, 2013, p. 306.

7 Especismo é um termo que designa a atribuição de maior peso aos interesses de membros da própria espécies, em caso de choque de interesses, com base exclusivamente no pertencimento a uma espécie. É, ainda, uma forma de preconceito orientado para o critério taxonômico. Cf:: SINGER, 2002, p. 68.
} 
O fundamento do tratamento jurídico de animais não deve ser, portanto, calcado no critério da espécie. A busca pela superação do especismo em conjunto com a consideração de animais para além da reificação gerou um grande número de teorias éticas que englobam a ética ou os direitos dos animais. No presente trabalho, serão abordados os três vieses mais discutidos no presente século: o abolicionismo, o recorte kantiano e o utilitarismo.

\section{TEORIAS ÉtICAS SOBRE O TRATAMENTO DE ANIMAIS E SUAS REPERCUSSÕES JURÍDICAS: O DEBATE ENTRE ABOLICIONISMO E BEM- ESTARISMO}

O Direito brasileiro, fortemente calcado na tradição romana, polariza em duas categorias binárias pessoas e propriedades. Nessa lógica, conforme dito, os seres pertencentes à espécie Homo sapiens encaixam-se como pessoas naturais - sujeitos de direito capazes de contrair obrigações e gozar de direitos na ordem civil. Animais, por sua vez, encaixam-se na categoria de bens, sujeitando-se à posse por pessoas naturais. Por isso, as pessoas possuem dignidade e os animais possuem um preço (KORSGAARD, 2013, p. 631).

A lógica binária do tratamento de animais e humanos no Direito brasileiro gera incongruências e, muitas vezes, ineficiência na aplicação das leis nos casos concretos. Ao mesmo tempo em que animais são tratados como propriedade, sujeitos a compra e venda e ao penhor, por exemplo, eles são vistos como um elo fundamental entre famílias e possuem uma importância cabal para a manutenção do meio-ambiente equilibrado. A incongruência gerada entre o tratamento legal dos animais e as situações concretas pode ser evidenciada no recente caso de invasão das dependências do Instituto Royal.

No dia 19 de outubro de 2013, diversos ativistas pelos direitos (dos) ${ }^{8}$ animais invadiram o laboratório do Instituto Royal, localizado na cidade de São Roque - São Paulo. Sob a alegação de que o laboratório executava pesquisas cruéis com modelos animais, dentre eles cães da raça beagle, o grupo de ativistas efetuou o resgate de mais de 170 cães. De acordo com relatórios do Ministério Público, as dependências do laboratório proporcionavam constante stress físico e psicológico aos animais ali presentes, além de estarem cobertas de fezes.

\footnotetext{
8 Ativistas pelos animais distinguem os termos direitos animais e direitos dos animais. A diferença encontra-se, para esse grupo, na busca de direitos que assemelham-se à lógica dos direitos humanos.
} 
A invasão do laboratório tornou-se, rapidamente, manchete dos principais jornais brasileiros. Também foi responsável por polarizar a opinião pública sobre o assunto da utilização de animais para testes de produtos. Ativistas e pessoas simpáticas à causa de defesa

animal alegavam que animais, por serem sencientes, mereciam tratamento diferenciado do dado atualmente. Já pessoas vinculadas ao laboratório afirmavam que agiam de acordo com a lei brasileira, para a qual os animais são bens.

Esse caso demonstra os problemas cotidianos enfrentados pelos juristas brasileiros no que tange à temática dos direitos dos animais. Ainda, revela que o binarismo humanosanimais, em voga no direito atual, é insuficiente para lidar com as situações cada vez mais complexas geradas pela interação entre humanos, animais e meio-ambiente.

A desconstrução da estatura valorativa superior dos seres humanos, bem como a não caracterização da maior parte dos animais com os quais travam-se relações atualmente como coisas impõe desafios à caracterização de uma relação juridicamente adequada entre humanos e animais. Intuitivamente, parece claro que animais encontram-se no diapasão entre pessoas e coisas. Entretanto, as implicações legais e práticas de adicionar-se uma nova categoria ao Direito brasileiro não devem passar despercebidas. Nesse sentido, a análise dos direitos dos animais perpassa tanto um viés eminentemente filosófico-epistemológico quanto um jurídicopragmático.

Em busca de respostas ao problema do caráter jurídico-filosófico da relação em análise, três abordagens buscam superar a inadequação do tratamento de humanos para com animais: a abolicionista, a kantiana e a utilitarista.

\subsection{O abolicionismo animal}

O viés abolicionista propõe que a utilização de animais para fins humanos é, em si, errada, e deve ser extinta, pois implica em uma exploração de seres que possuem valores que são inatos. Nesse sentido, animais não devem ser nunca tratados juridicamente como bens, ou mesmo sujeitos a uma disciplina de propriedade.

Para Gary Francione, jurista abolicionista, o tratamento de humanos para com animais pode ser descrito como "moralmente esquizofrênico" (FRANCIONE in SUNSTEIN. NUSSBAUM, 2005, p. 108). Isso porque, muito embora o ordenamento jurídico e as próprias pessoas aleguem que os animais são levados em consideração, os interesses dos animais são 
cotidianamente ignorados. Para Francione, um fator que contribui sobremaneira para que os interesses de animais não sejam levados em consideração está na caracterização jurídica de animais como propriedade.

O que faz com que Francione afirme que a atitude jurídica para com animais é esquizofrênica é o fato de que existem leis e regimentos para que os animais sejam protegidos, mas essa proteção não atinge nenhum real interesse desses animais, havendo um forte descompasso entre a proteção dada e a proteção merecida.

De acordo com o viés abolicionista, a proteção jurídica dada aos animais é, via de regra, a que coincide com o princípio do tratamento humanitário. De acordo com esse princípio, os animais têm direito a uma forma mínima de bem-estar. Para tanto, deve-se proteger os animais no que tange a crueldade e ao gozo de animais como propriedades humanas. Ainda, o princípio do tratamento humanitário indica que é possível usar os animais, mas apenas quando houver necessidade e sob a mínima imposição de sofrimento (FRANCIONE, 2013, p. 58).

Entretanto, para abolicionistas como Francione, não é possível justificar o uso de animais sob o véu da mínima imposição de sofrimento. O conflito de interesses que justifica o uso de animais é, para abolicionistas, apenas aparente.

Isso ocorre, pois o uso que é dado a grande parte dos animais atualmente não pode ser, de acordo com Francione, considerado como um verdadeiro interesse. O autor exemplifica o seu raciocínio através de exemplos como o uso de animais para vestuário e o consumo de produtos de origem animal como alimento.

No que tange ao uso de animais para vestuário, Francione afirma que os animais utilizados para a produção de casacos de pele, por exemplo, sofrem consideravelmente, para que os seres humanos possam utilizar-se de vestimentas perfeitamente confeccionáveis a partir de materiais sintéticos. Estima-se que mais de 40 milhões de animais sejam abatidos para que peças de vestimenta possam ser confeccionadas. Para o autor, "há muitas alternativas, como o algodão e os tecidos sintéticos, que tornam inteiramente desnecessário o uso de qualquer animal para vestuário" (FRANCIONE, 2013, p. 83). O descompasso entre a necessidade e o sofrimento dos animais é, para Francione, critério suficiente para que o uso de animais para vestimenta seja completamente abolido, não sendo este passível de tutela jurídica que venha a regulamentar.

Ainda, outro âmbito injustificado para o viés abolicionista é o concernente à utilização de animais para a alimentação. Em termos numéricos, a maior parte dos animais utilizados para fins humanos encontra-se no setor alimentício. O resultado da utilização de 
animais como produtos alimentícios implica, via de regra, na aplicação da lógica industrial padrão para a produção de carne: “os animais [devem ser] criados nos menores espaços possíveis e nas instalações mais baratas, e [devem ser] alimentados com a comida de mais baixo preço, de um modo que requeira o mínimo de trabalho humano possível” (FRANCIONE, 2013, p. 59).

O resultado da lógica industrial aplicada aos animais é, segundo o viés abolicionista, devastador. Animais sofrem da privação de luz e das demais condições necessárias para que eles desenvolvam uma vida saudável, como um espaço adequado e limpo e um meio-ambiente balanceado. $\mathrm{O}$ abate e a produção de derivados de animais gera sofrimento, e esse é, também, injustificado - o que enseja a abolição do uso de animais para fins alimentícios.

Essa inexistência de justificativa se dá a partir da constatação de que, segundo Francione, “[n]ão é necessário, de modo algum, que os humanos comam carne ou outros produtos animais". Para o autor, órgãos como o Departamento de Agricultura dos Estados Unidos (U.S. Department of Agriculture) e a Associação Dietética Americana (American Dietetic Association) reconhecem que uma dieta estritamente vegana, associada à suplementação da vitamina B12, pode fornecer aos organismos humanos os nutrientes necessários para a manutenção da saúde.

Ainda, argumenta-se que o impacto ambiental gerado pela produção nos moldes atuais de derivados de animais para alimentação é alto. Observa-se que os animais consomem seis vezes mais proteínas do que produzem. E 40 por cento dos grãos utilizados no mundo inteiro é destinado à produção de carnes, o que gera um cálculo negativo de produção de alimentos e que impacta o ecossistema mundial de modo negativo. Recursos como água e energia também são consumidos massivamente para a produção de alimentos de origem animal, sendo que quase 90 por cento da água potável mundial consumida é utilizada para a produção agrícola e na de rebanhos, sendo que a produção de proteína animal consome nove vezes mais água potável que a de proteína vegetal (FRANCIONE, 2013, p. 64-65).

Em resumo, esses usos não se justificam pois geram sofrimentos desnecessários e podem ser substituídos por métodos alternativos de produção tanto de vestuário quanto de alimentos.

A esquizofrenia moral de que tanto fala Francione é gerada a partir da noção jurídica de que animais são propriedade. Essa noção é importante para a cultura jurídica do ocidente como um todo, uma vez que os direitos de propriedade possuem eminente destaque nos ordenamentos e a afirmação de que animais são propriedades coincide com o hiato que divide humanos como sujeitos de direito e animais como objetos de tutela. 
No Direito brasileiro, por exemplo, os animais são bens semoventes. Isso implica que eles podem ser possuídos do mesmo modo que demais objetos dotados de movimento próprio, e regulam-se como propriedades. O proprietário de um animal pode utilizá-lo com objetivos econômicos, de lazer, ou como garantia.

Para Francione, quando se estabelece uma hierarquia entre proprietário e bem, é impossível avaliar acuradamente os interesses em questão, já que, independente do que está em jogo, a polarização entre quem detém e quem é detido sempre irá pender para o lado que o detentor quiser.

O fato que confere limites ao tratamento de humanos para os animais, para os abolicionistas, não é a preservação do bem-estar do animal, mas sim a aplicação do princípio da igual consideração aos interesses do animal. De acordo com esse princípio, todos os interesses comparáveis devem ser analisados em pé de igualdade. Já que tratar animais como propriedade acarreta, para Francione, em um óbice ao reconhecimento de qualquer interesse dos animais que extrapole os requeridos para que humanos atinjam os seus objetivos (2013, p.

178), a primeira implicação do princípio da igual consideração aos animais é a de que animais não podem ser propriedade. Como a aplicação do princípio implica em haver a obrigação de proteger os animais "contra todo sofrimento resultante de seu uso como propriedade humana”, conclui Francione, “[deve-se] dar aos animais, como (...) aos humanos, o direito básico de não serem tratados como recursos" (2013, p. 180).

A conclusão lógica da descaracterização abolicionista de animais como bens é a caracterização de animais como pessoas. Francione, em especial, afirma que, para o Direito, ou se é coisa ou se é pessoa. Nesse sentido, ou os animais

\footnotetext{
são pessoas, seres aos quais o princípio da igual consideração se aplica e para com os quais temos obrigações morais diretas, ou eles são coisas, seres aos quais o princípio da igual consideração não se aplica e para com os quais não temos nenhuma obrigação moral direta (FRANCIONE, 2013, p. 181-182).
}

Em suma, para o viés abolicionista dos direitos em relação aos animais, esses não podem ser caracterizados, sob nenhuma ótica, como propriedade, já que esse status importa em violação ao princípio da igual consideração, ao qual os animais fazem parte por serem seres sencientes - capazes de sentir dor e prazer. Como corolário da mudança de status jurídico, os animais não-humanos devem ser tratados a exemplo dos humanos: como pessoas. 


\title{
3.2. O viés kantiano: bem-estarismo indireto
}

A justificativa de matriz kantiana que fundamenta a perspectiva da relação entre humanos e animais é desenvolvida, principalmente, por Christine Korsgaard. Em síntese, Korsgaard afirma que a fórmula da humanidade, o Imperativo Categórico, não é passível de extensão aos animais. Entretanto, isso não impede que haja um senso de dever em relação aos animais.

De acordo com Immanuel Kant, cada ser humano possui um valor intrínseco, ou dignidade. Isso implica na categorização de pessoas como cidadãos no reino dos fins - isto é, pessoas capazes de confeccionar as suas próprias normas por meio das escolhas. Por isso, pessoas não devem ser tratadas como meios para fins alheios. Para Kant, se existe algo como um Imperativo Categórico, deve haver, também, algo cuja existência "em si possua um valor absoluto, algo que, como um fim-em-si, pode ser fundamento para leis determinadas" (KANT in KORSGAARD, 2013, p. 631).

Nesse sentido, deve-se agir de forma que a humanidade seja sempre tratada, "seja na sua própria pessoa ou na pessoa do outro, sempre ao mesmo tempo como um fim, nunca meramente como um meio" (KANT, 1997, p. 38).

O status de fim-em-si - e de formadores do reino dos fins - é conferido a humanos, já que Kant identifica a própria humanidade com a natureza racional do ser, assim dotada de autonomia e dignidade. Animais, por outro lado, não seriam seres racionais ${ }^{9}$, no sentido kantiano. A eles faltaria uma tônica bastante valorizada: a esfera valorativa. Valores, nesse sentido, são criações humanas mediadas pela racionalidade. Animais, por serem:

\begin{abstract}
seres desprovidos de razão possuem apenas um valor relativo, como meios, e são, portanto, chamados de coisas, ao passo que seres racionais são chamados de pessoas, devido à sua natureza, o que os marca como um fim em si (KANT, 1997, p. 37).
\end{abstract}

Nesse sentido, a distinção kantiana entre seres humanos e animais é traçada na medida em que aqueles são capazes de construir uma ordem transcendental e racional para o valor de suas vidas, e esses, em contrapartida, não.

\footnotetext{
9 Muito embora possam ser inteligentes. Cf. KORSGAARD, Christine. Fellow Creatures. Tanner Lecture on Human Values at the University of Michigan. p. 9. Disponível em: < www.TannerLectures.utah.edu >. Acesso em: 10 Mai. 2015.
} 
Não obstante, um tratamento violento e cruel direcionado a animais é uma oposição ao cultivo dos deveres de humanidade, imiscuídos em cada ser racional. Seres humanos, capazes de legislar sobre si mesmos, compartilham uma esteira natural com os animais. Nesse sentido, tratamentos cruéis para com animais desonram os deveres humanos consigo mesmos.

\title{
3.3. O utilitarismo: a consideração dos interesses de sencientes
}

Outra via argumentativa é a utilitarista. O utilitarismo tem a sua raiz no pensamento de Jeremy Bentham (1748-1932) e de John Stuart Mill (1806-1873). Via de regra, o argumento utilitarista busca a maximização da soma total de satisfação de interesses, ou, ainda, a minimização das formas de sofrimento.

Tendo isso em foco, já os primeiros utilitaristas tinham em mente a defesa de interesses não-humanos com base no princípio da maximização da soma total de satisfação de interesses de criaturas capazes de sofrer. Conforme Henry Sidgwick,

\begin{abstract}
deve-se considerar (...) o que "nós" significa, a alegria de quem deve ser levada em consideração. Deve-se estender a preocupação a todos os seres capazes de prazer e dor que são afetados por nossas condutas? Ou deve-se confinar a visão à alegria humana? O primeiro viés é aquele adotado por Bentham e Mill, e (acredito), pela escola utilitarista em geral: e está obviamente mais de acordo com a universalidade que é a característica do princípio deles. É o bem universal, interpretado e definido como 'alegria' ou 'prazer', que um utilitarista considera como um dever a ser atingido: e parece arbitrário e desarrazoado excluir do fim, concebido dessa forma, qualquer prazer de qualquer ser senciente (SIDGWICK, 1981, p. 414).
\end{abstract}

De todas as teorias sobre o estatuto ético-jurídico de animais e da regulação da relação entre espécies, o utilitarismo é a que mais chama a atenção para a importância da consideração da senciência de animais.

Via de regra, o argumento utilitarista aplicado à relação em destaque estabelece que todos os seres sencientes, isto é, capazes de processarem cognitivamente dor e prazer, possuem interesses - ao menos o interesse de não sentirem dor - que devem ser analisados em pé de igualdade. A centralidade da noção de senciência para o utilitarismo se justifica pois

a capacidade de sofrer e desfrutar as coisas é uma condição prévia para se ter quaisquer interesses, condição que é preciso satisfazer antes de se poder falar de interesses, e falar de um modo significativo (...). Se um ser sofre, não pode haver nenhuma justificativa de ordem moral para nos recusarmos a levar esse sofrimento em consideração (...) em termos de igualdade com o sofrimento semelhante (SINGER, 2002, p. 67). 
Nesse sentido, de acordo com Peter Singer, o princípio da igual consideração de interesses implica que "a nossa preocupação com os outros não deve depender de como são, ou das aptidões que possuem" (SINGER, 2002, p. 66). Ainda, se um ser é submetido a formas penosas de tratamento, isso deve compor um espectro de preocupações morais que, por sua vez, devem ser traduzidas como proteções jurídicas. A senciência é, portanto, um limite de preocupação moral.

Entretanto, a igualdade aplicada à consideração de interesses independentemente das espécies não é independente das características particulares que determinados seres, em determinados contextos, venham a possuir. Via de regra, seres humanos têm aptidões mentais que, em determinadas situações, são responsáveis por gerar um maior sofrimento do que o dos animais. Afirma Peter Singer que o terror gerado pela expectativa de sofrimento por antecipação em humanos submetidos a tratamentos cruéis tende a ser pior do que aquela sofrida por animais como camundongos, já que "[o] terror resultante seria uma forma adicional de sofrimento, vindo somar-se à dor provocada pela experiência" (2002, p. 69).

Nesse sentido, é possível justificar, por modos não-especistas, a preferência pela utilização de determinados animais para experimentos delimitados.

\subsection{Uma visão geral sobre as teorias éticas sobre o tratamento de animais}

O estudo dos direitos dos animais no Brasil ainda é bastante genérico. Usualmente, a análise dos direitos subdivide-se em duas categorias. A primeira delas diz respeito à inclusão dos animais em uma categoria robusta de direitos, como a dos sujeitos de direito. Nessa categoria encontram-se os abolicionistas. Por outro lado, a segunda categoria engloba análises que não colocam animais como sujeitos diretos de direito, mas como uma categoria que merece cuidados especiais no que tange ao bem-estar. De acordo com Tom Beauchamp, a primeira categoria

\footnotetext{
é geralmente retratada como favorável aos direitos para animais como o direito à vida, direito a um habitat não contaminado (...). Quem defende os direitos animais busca abolir o uso de animais em pesquisas biomédicas, na produção de comida, na indústria de entretenimento, zoológicos (...). Bem-estarias, por outro lado, são retratados como detentores de perspectivas utilitaristas ou pragmáticas, que reconhecem as obrigações humanas de não causar sofrimento ou perda indevida de liberdade, mas permitem que muitos usos de animais sejam justificados, quando já um amplo benefício das partes levadas em consideração (BEAUCHAMP in: FREY, BEAUCHAMP, 2013, p. 200).
} 
No presente trabalho, propor-se-á que a polarização, frequentemente abordada em sede de direitos dos animais, entre abolicionismo e bem-estarismo é inócua e incapaz de lidar com o largo espectro que a questão dos direitos a serem conferidos aos animais apresenta.

A querela da relação entre humanos e animais não depende nem de abolicionismo nem de bem-estarismo. Depende, acima de tudo, do abandono de busca por soluções tudo ou nada.

\section{ANIMAIS DESIGUAIS EM CONTEXTOS DESIGUAIS: UMA PROPOSTA DE SUPERAÇÃO DA DICOTOMIA ENTRE PESSOAS E COISAS}

As teorias éticas sobre o tratamento adequado de animais no Direito buscam fornecer respostas ao enquadramento de animais como coisas, pessoas ou como uma terceira categoria especial, estrategicamente localizada entre sujeitos e objetos de direito. Nesse sentido, a resposta abolicionista indica que animais são pessoas, e devem destacar-se do status de propriedade; a resposta kantiana confere aos animais um status de propriedades com tutelas especiais, de acordo com suas características; e, por último, a resposta utilitarista afirma que os animais não devem ser destacados da categoria jurídica das coisas e alguns deles devem ser considerados como pessoas, como é o caso dos grandes primatas (SINGER, 2002, p. 119126).

Muito embora as teorias abordadas tenham diferenças práticas, elas compartilham um pressuposto. Assume-se que a forma adequada de se abordar o tratamento ético de animais depende da relação entre um indivíduo e as suas capacidades. Em outras palavras, "a resposta à questão de como um indivíduo pode ser tratado depende de como o indivíduo se qualifica para um tipo geral de status, o qual, por sua vez, depende da posse, por um indivíduo, de algumas características gerais" (RACHELS in SUNSTEIN, NUSSBAUM, 2005, p. 167).

Essa forma de raciocínio, entretanto, fornece pouca base para que o tratamento de animais seja efetivamente justificado. Isso porque a relação entre um indivíduo $(I)$ e as características $(C)$ desse indivíduo $(I)$ não gera, por uma soma simples entre si, um tratamento (T) adequado a todas as situações concretas. Por incrível que pareça, os três recortes éticos abordados acima possuem apelo prático insuficiente. A insuficiência prática, portanto, das três categorias encontra-se na insuficiência do pressuposto adotado por todas elas. 
A relação válida entre $I$ e $C(i)$ somente é capaz de gerar um resultado ética e juridicamente válido $T$ se e somente se outra variável é inserida na equação. Essa variável corresponde ao papel desempenhado pelo ambiente informacional $(A)$ situado geográfica $(g)$ e temporalmente $(t)-A(g, t)$ - em que seres e agentes estão inseridos.

As características que um indivíduo possui são, via de regra, muito importantes. Sabe-se que elas são indicadores de tipos de tratamento jurídico. Tome-se como exemplo o seguinte caso: um adolescente de 16 anos necessita da assistência de uma pessoa maior de idade para executar determinados atos da vida civil. Nesse caso, a característica que indica o tipo de tratamento é a idade da pessoa - um dos critérios adotados no Brasil para indicar um desenvolvimento incompleto de sua autonomia.

Entretanto, é necessário perceber que uma característica que justifique uma determinada forma de tratamento pode não ser a mais adequada para a justificação de outras. No caso do adolescente de 16 anos, a característica da idade pode justificar a necessidade de assistência dos pais para atos com repercussão civil. Entretanto, o critério da idade, vinculado à autonomia, não é adequado para justificar que um adolescente sofra ou não castigos físicos de seus parentes caso haja algum "mau comportamento".

Ele não é adequado pois o tratamento jurídico a ser dado na questão não envolve diretamente a autonomia, mas sim a capacidade de sofrer que esse adolescente possui. Sendo assim, a idade ou o grau de autonomia do adolescente são insuficientes para que se diga que castigos físicos são errados - a característica da idade, tão importante para atos da vida civil, não é o que importa nesse outro cenário.

Nesse sentido, é possível afirmar que as características só são relevantes juridicamente quando elas estão contextualizadas, isto é, inseridas em um universo de sentido e em interação com ele. Por isso, James Rachels afirma que

não existe uma característica, ou um conjunto razoável de características,
responsável por separar algumas criaturas das outras, no que diz respeito ao
merecimento de um tratamento respeitoso. Essa é a forma errada de se pensar sobre
a relação entre as características de um indivíduo e como ela ou ela deve ser tratado.
Ao invés disso, tem-se um conjunto de características e um conjunto de tratamentos,
cada característica sendo relevante para justificar alguns tratamentos, mas não outros
(RACHELS in SUNSTEIN, NUSSBAUM, 2005, p. 169).

Observe-se o caso recente envolvendo uma espécie peculiar de animais: as abelhas. A morte de um enxame de abelhas não parece, em um primeiro momento, um problema juridicamente relevante. Nesse sentido, é exagerado e injustificado afirmar que deveria haver 
alguma sanção jurídica para um morador alérgico à picada de abelha que espante de sua residência um enxame que ali faz colmeia.

Todavia, em outros contextos, as abelhas, devido ora às características que possuem, ora ao ambiente em que se encontram, ganham extrema relevância jurídica. Esse cenário é perceptível através da redução drástica do número de abelhas no mundo e os efeitos na produção de alimentos

Sabe-se que, nos últimos anos, a quantidade de abelhas espelhadas pelo globo tem se reduzido, o que caracteriza o fenômeno chamado "síndrome do colapso da colônia". Dados mais recentes indicam que $42 \%$ das abelhas dos Estados Unidos desapareceram em um período de apenas um ano, e estima-se que no mundo essa redução foi de até 53\% somente no ano de 2012 (BEER, 2015).

Ainda é incerto o motivo que levou à redução das comunidades desses insetos. Aponta-se, entretanto, como causa principal, o uso massivo de pesticidas em plantações - em especial os pesticidas da classe dos neonicotinoides. Esses, de acordo com o agrônomo Aroni Sattler, "têm uma segurança grande com relação aos mamíferos, principalmente o homem, por isso são bastante utilizados. O problema é que eles afetam não apenas os insetos que são considerados pragas, mas os polinizadores também" (SATTLER in SANTOS, 2014).

A redução dos enxames é um problema multifatorial. Isso porque ela não implica somente no desaparecimento de um conjunto de determinados animais. Sabe-se que as abelhas são as principais polinizadoras associadas ao florescimento "da flora e à maior parte do cultivo agrícola" (BEER, 2015). Nessa lógica, quanto menos abelhas, menor será a produção de alimentos e insumos para fins tanto humanos quanto animais - redução que pode chegar a $70 \%$.

Pode-se concluir que o tratamento juridicamente adequado às situações sempre opera em função da relação entre características individuais ou coletivas e ambiente, capazes de equacionarem uma forma adequada de tratamento jurídico ao caso concreto. Nesse sentido, é possível afirmar que um ser senciente deve ter um tratamento jurídico que o possibilite evitar ao máximo dor e sofrimento, ao passo que um ser autoconsciente deve ter um tratamento que o proteja da condição de ser humilhado (RACHELS in SUNSTEIN, NUSSBAUM, 2005, p. 173).

Assim, o que se extrai dessa ideia é o fato de que o tratamento jurídico deve ser adequado ao conjunto de características que constitui razões relevantes para que um ser seja ou não submetido a determinado tratamento. Nesse sentido, inexiste uma resposta única para 
a forma através da qual os animais devem ser tratados. Isso se justifica pela importância dada tanto às suas características principais quando àquela conferida ao papel dessas características no ambiente.

Para além da personificação ou da reificação de animais, a interação entre o contexto informacional em que animais estão inseridos e as suas características é fundamental para que seja possível pensar no tratamento jurídico dos animais. Com isso, a justificativa do tratamento jurídico de animais deixa de pertencer ao domínio da divisão das espécies e da dicotomia entre coisas e pessoas.

Isso ocorre pois é virtualmente impossível delimitar critérios únicos que sejam capazes de justificar uma diferença de tratamento jurídico entre humanos e animais, caso a dicotomia de espécies seja superada. A exemplo do afirmado pelo filósofo da biologia David Hull,

[o] desejo de encontrar alguma característica genética exclusiva de todos os seres humanos, e inexistente nos seres não-humanos, é irresistível. Mas, qualquer que seja o traço escolhido, ou algumas pessoas não o exibem ou então membros de outras espécies o possuem (HULL in INGOLD, 1995, p. 10).

O tratamento juridicamente adequado de animais, portanto, deve superar a dicotomia entre coisas e pessoas. Antes, é necessário compreender a importância que emerge da interação entre os indivíduos, suas características e o ambiente situado geográfica e temporalmente, para que o tratamento jurídico seja endereçado de forma a proteger a maior parte dos interesses envolvidos: sejam eles animais, humanos ou ambientais.

\section{CONCLUSÃO}

A proposta do presente trabalho é a de oferecer uma justificativa ético-jurídica para o tratamento de animais que supere a dicotomia entre coisas e pessoas. Para tanto, buscou-se desconstruir a importância da noção de espécie como critério normativo no Direito, denotando a sua invalidade jurídica. Ainda, analisou-se as principais teorias éticas que visam à superação da lógica especista e as suas repercussões jurídicas.

Por fim, buscou-se apresentar um viés alternativo às proposições atuais em sede de direitos dos animais. Nesse sentido, sustentou-se que os animais sejam juridicamente analisados em função da interação entre as características que possuem e o ambiente em que 
se inserem, denotando uma eminente importância tanto de suas funções ambientais quanto de seus nichos ecológicos.

Com isso, pretende-se evitar a ruptura entre os domínios humano e animal, propondo, em sentido contrário, o que o antropólogo Tim Ingold (2000, p. 60) caracteriza como "antropologia ecológica". Essa, ao invés de propor uma ruptura radical entre os domínios dos seres humanos - frequentemente caracterizados como sociais - e os domínios dos animais - caracterizados como ecológicos, entende que aqueles são um subconjuntos desses.

A proposta dessa antropologia ecológica sugere que a humanidade deva engajarse ativamente com os elementos que constituem o seu mundo, como animais e ambientes:

[o] primeiro passo para se estabelecer essa antropologia ecológica está em reconhecer que as relações nas quais ela se insere, entre humanos e ambiente, não estão confinadas ao domínio da natureza, separadas e dadas independentemente do domínio em que eles levam as suas vidas como pessoas (INGOLD, 2000, p. $60)$.

Nesse viés, é possível afirmar que pessoas não são desvinculadas e passivas diante do ambiente. Da mesma forma, animais não são desvinculados e passivos diante do ambiente. Humanos e animais, devido ao seu envolvimento mútuo, são "centros de ação e consciência, situados dentro de um processo de vida contínuo" (INGOLD, 2000, p. 59).

\section{REFERÊNCIAS BIBLIOGRÁFICAS}

BEER, Raquel. Casa Branca faz do sumiço de abelhas uma questão de Estado. Veja, 23 mai. 2015. Disponível em: <http://veja.abril.com.br/noticia/ciencia/casa-branca-faz-dosumico-de-abelhas-uma- questao-de-estado >. Acesso em: 01 ago. 2015.

BOCQUET-APPEL, Jean Pierre. When the world's population took off: the springboard of the neolithic demographic transition. Science, vol. 333, nº 6042, 2011, p. 560-561.

BUCHANAN, Allen. Better than human: the promise and perils of enhancing ourselves. Oxford: Oxford University Press, 2011.

CANADÁ, Conselho Canadense sobre Cuidados Animais. CCAC 2011 Survey of Animal Use, Dez. 2010.

CRANE, Tim. PATTERSON, Sarah. History of the mind-body problem, London: Routledge/Taylor and Francis e-library, 2002. 
CRESCE o mercado para produtos de animais de estimação. Bauru e Marília, Gl, 10 jan. 2015. Disponível em: <http://g1.globo.com/sp/bauru-marilia/mundopet/2014/noticia/2014/12/mundo-pet- cresce-o-mercado-de-produtos-para-animais-deestimacao.html>. Acesso em: 17 mai. 2015.

DESCARTES, René. Meditations on first philosophy. With selections from the objections and replies. Oxford: Oxford University Press, 2008.

ESTADOS UNIDOS, Departamento de Agrigultura, Serviço de Inspeção de Saúde de Animais e Plantas. Annual Report Animal Usage by Fiscal Year, 28 Nov. 2014.

FANTÁSTICO mostra falta de higiene em abatedouros e abate cruel dos gados. Rio de Janeiro, $\quad$ Gl, $10 \quad$ Mar. 2013. Disponível em: < http://g1.globo.com/fantastico/noticia/2013/03/fantastico-mostra-falta- de-higiene-emabatedouros-e-abate-cruel-dos-gados.html>. Acesso em: 10 Mai. 2015.

FERNANDEZ-ARMESTO, Felipe. Então você pensa que é humano? Uma breve história da humanidade. Trad. Rosaura Eichemberg. São Paulo: Companhia das Letras, 2007.

FLORIDI, Luciano. The informational nature of personal identity. Minds and machines, vol. 21, 2011. FRANCIONE, Gary. Introdução aos direitos animais: seu filho ou o cachorro? Trad. Regina Rhoda. Campinas: Editora Unicamp, 2013.

FREY, Raymond. BEAUCHAMP, Tom (eds). The Oxford Handbook of Animal Ethics. Oxford: Oxford University Press, 2013.

GALVÃO, Pedro (ed). Os animais têm direitos? Lisboa: Dinalivro, 2010.

IBGE. Indicadores IBGE: estatística de produção pecuária. Junho de 2014. Disponível em:

<http://www.ibge.gov.br/home/estatistica/indicadores/agropecuaria/producaoagropecuari a/abate-leite- couro-ovos_201401_publ_completa.pdf $>$. Acesso em 10 Mai. 2015.

INGOLD, Tim. Humanidade e animalidade. Revista Brasileira de Ciências Sociais. Disponível em:

<http://www.anpocs.org.br/portal/publicacoes/rbcs_00_28/rbcs28_05.htm>. Acesso em 01 ago. 2015.

The perception of the environment: essays on livelihood, dwelling and skill. New York: Routledge, 2000.

KANT, Immanuel. Groundwork of the Metaphysics of Morals. Cambridge: Cambridge University Press, 1997.

KORSGAARD, Christine. Fellow Creatures. Tanner Lecture on Human Values at the University of Michigan. p. 9. Disponível em: <www.TannerLectures.utah.edu $>$. Acesso em: 10 Mai. 2015. 
Studies, vol. 33, nº 4, p. 629-648, 2013.

LOCKE, John. An essay concerning human understanding. London: Oxford University Press, 1964. ORGANIZAÇÃO DAS NAÇÕES UNIDAS. Declaração Universal dos Direitos Humanos (1948). ORGANIZAÇÃO DOS ESTADOS AMERICANOS. Pacto de San José da Costa Rica (1978).

REINO UNIDO, Estatísticas Anuais dos Procedimentos Científicos em Animais Vivos na Grã Bretanha, 10 Jul. 2014.

SANTOS, Juliana. As abelhas estão desaparecendo. E isso é preocupante. Veja, 01 jan. 2014. Disponível em: <http://veja.abril.com.br/noticia/ciencia/as-abelhas-estaodesaparecendo-e-por-que- devemos-nos-preocupar>. Acesso em: 01 ago. 2015.

SIDGWICK, Henry. The methods of ethics. 7.ed. Indianapolis: Hackett Publishing Co., 1981. SINGER, Peter. Ética Prática. Trad. Jefferson Camargo. 3.ed. São Paulo: Martins Fontes, 2002.

STANCIOLI, Brunello. Renúncia ao exercício de direitos da personalidade, ou, como alguém se torna o que quiser. Belo Horizonte: Del Rey, 2010.

SUNSTEIN, Cass. NUSSBAUM, Martha (eds). Animal rights: current debates and new directions. Oxford: Oxford University Press, 2005. 